Журавлев А.Л.

\title{
Экономическая психология: место и роль в современной науке
}

В статье рассматриваются внутренние и внешние причины интенсивного развития экономической психологии как научнопрактической отрасли психологии, влияние ее на развитие современной психологической науки. Анализируются понятия экономической психологии: экономическое сознание, экономическое поведение, субъекты экономической активности (личность, малые и большие группы).

Особое внимание уделяется двойному статусу экономической психологии (в экономической и психологической науках, различию их исследовательских парадигм), а также междисциплинарным связям с этикой и психологическими дисциплинами (социальной психологией, психологией управления). Отмечается более интенсивное развитие внутрипсихологического уровня междисциплинарных исследований $в$ экономической психологии, по сравнению с внешнепсихологическим.

Ключевые слова: причины, экономическое сознание, экономические объекты, субъекты экономического поведения, междисциплинарность экономической психологии.

Основные френомены и понятия экономической психологии. В последние 10-15 лет в нашей стране очень активно возрождается и фактически по-новому развивается экономическая психология как отрасль психологической науки, смежная с экономической наукой. Интенсивность развития любой отрасли знания, в том числе и экономической психологии, не может зависеть от какой-то одной группы факторов или причин, так как такие сложнейшие явления в науке всегда имеют множество определяющих их факторов. Нередко встречающееся в публикациях утверждение о том. что отечественная экономическая психология интенсивно развивалась именно в 90-е годы XX века, наверное, не потребует от историков психологической науки больших доказательств в будущем. Сейчас это утверждение воспринимается как более-менее очевидное. Главная из многих причин ее интенсивного развития заключена в социально-экономическом состоянии российского общества в 90-е годы, в его практических потребностях и запросах к различным отраслям науки, в том числе экономической психологии. Острая актуальность ее развития в первую очередь определялась практическими причинами. 
Конечно, объясняя феномен интенсивного развития отечественной экономической психологии, никак нельзя умалять значение и других причин, а именно: а) состояния внутренней готовности и возможностей самой психологической науки: теоретических (концептуальных), методических (инструментальных), практических, наличия профессионально подготовленных специалистов и т.п. - это относится к внутрипсихологическим причинам; б) заинтересованности других наук, но прежде всего экономической науки, в получении дополнительных фрактов, закономерностей, объяснительных схем для решения вопросов, пограничных с психологической наукой, ее востребованности специалистами из других областей научного знания - это составляет внешнепсихологические причины; в) наличия у психологической науки накопленного исторического опыта интенсивного фрормирования научно-практических отраслей психологии в ответ на острые практические потребности общества в конкретный исторический период его развития - это историкопсихологические причины.

Экономическая психология по сути призвана изучать экономикопсихологические явления (феномены) во всей их совокупности: экономико-психологические процессы, состояния и свойства самых различных субъектов. Однако, несмотря на огромное многообразие таких явлений, главные среди них - это феномены экономического сознания и экономического поведения и соответствующие им основные понятия, используемые в экономической психологии.

Под экономическим сознанием понимается частная форма индивидуального или группового сознания, заключающаяся в разных фрормах знания индивидуального и группового субъекта о различных экономических объектах и его отношении к этому знанию. К основным феноменам индивидуального и группового экономического сознания, которые изучаются в современной экономической психологии, относятся следующие:

- социальные представления об экономических объектах, как реальных, так и идеальных;

- отношение к экономическим объектам, а также мнения и суждения о них, их оценки и т.п.;

- социальные установки, стереотипы и предрассудки, связанные с экономическими объектами;

- осознаваемые эмоции, чувства и в целом переживания, связанные с экономическими объектами;

- френомен социальных ожиданий, предвосхищения, прогноза экономических изменений, т.е. предстоящих событий, связанных с экономическими объектами; 
- социальная категоризация и интерпретация экономикопсихологических явлений и др.

Перечисленные феномены экономического сознания не имеют какого-то единого основания их выделения, более того, они частично перекрывают друг друга по своему содержанию и обозначаются терминами из разных теоретических подходов к исследованию экономического сознания. Однако здесь они вместе представлены потому, что, хотя и в принципиально различной степени, реально изучаются как психологические феномены экономического сознания в современной социальной и экономической психологии.

Если судить по современным публикациям из названных отраслей психологической науки, то под экономическими объектами, знание о которых и отношение к которым составляют сущность экономического сознания, чаще всего понимаются следующие:

- заработная плата, прибыль, материальная обеспеченность или в целом экономические условия жизни различных экономических субъектов;

- богатство и богатые люди;

- бедность и бедные люди;

- различная собственность и ее собственники;

- деньги, твердая валюта или драгоценности;

- различные ценные бумаги как эквиваленты денег: акции, финансовые чеки, счета и т.п.;

- сбережения на счетах банков и тому подобных финансовых структур и др.

Тесно связанное с экономическим сознанием экономическое поведение подразумевает разные внешне проявляющиеся формы активности индивидуального и группового субъекта по отношению к различным экономическим объектам. Важнейшими среди них являются, например:

- реальный выбор фрормы экономической активности (наемного труда, коллективной формы собственности, предпринимательства и т.п.);

- реальная экономическая активность с ее многочисленными содержательными и формально-динамическими психологическими характеристиками;

- различные формы экономического поведения: потребительского, сберегающего, инвестиционного и т.д.

В последнее десятилетие в экономической психологии, особенно отечественной, все чаще стали использоваться более обобщенные (интегральные), по сравнению с экономическим сознанием и поведением, понятия «экономическая (или хозяйственная) активность» и как ее содержательный синоним «экономическая жизнедеятельность», а также 
некоторые другие понятия, близкие к ним. Потребность в подобных обобщенных понятиях вызвана необходимостью изучения таких экономико-психологических френоменов, в которых интегрируются разные феномены экономического сознания и формы экономического поведения, представить и анализировать разрозненно которые чрезвычайно трудно, а практически и невозможно. Хотя необходимо отметить, что в подавляющем большинстве исследований по-прежнему предпочтение отдается изучению феноменов экономического сознания личности и социальной группы.

Традиционными для экономической психологии субъектами экономической активности (жизнедеятельности) являются следующие три: личность (в некоторых системах используется более широкое понятие «человек»); малые группы и прежде всего первичные трудовые коллективы; большие социальные группы, среди которых, как правило, изучаются различные социально-экономические (или имущественные) и социально-демографические. Если говорить также о некоторых предпочтениях в современных экономико-психологических исследованиях, то они явно на стороне личности и больших социальных групп как субъектов экономической активности.

Соотношение экономической и социальной психологии. Положение экономической психологии в системе психологической науки пока очень слабо отрефлексировано профессиональным сообществом, сохраняются нерешенными многие вопросы теоретического содержания, обычно сопровождающие становление любой новой отрасли психологического знания и требующие достаточно продолжительных периодов для своего решения. Наиболее остро обсуждается вопрос о соотношении экономической психологии с социальной психологией. Следует особо отметить, что в этом состоит некоторая более общая закономерность возникновения и становления целого ряда современных отраслей психологической науки, так как подобные же обсуждения идут вокруг статуса организационной, исторической, политической, кросскультурной психологии и др.

Рассмотрим несколько возможных вариантов решения вопроса о соотношении экономической и социальной психологии, которые с разной частотой встречаются в литературе.

1. Экономическая психология является частным разделом прикладной социальной психологии. Такой вариант предполагает, что в экономической психологии не порождаются какие-либо новые закономерности социального поведения, а в частной и конкретной форме реализуются общие социально-психологические закономерности. При этом полностью используется понятийный аппарат социальной психологии и не 
предполагается разработка каких-либо специальных методов исследования.

2. Экономическая психология есть и теоретическая, и практическая отрасль социальной психологии, она разрабатывает теорию и практику экономического поведения людей (индивида и социальных групп) как конкретной формы социального поведения, но имеющей большую специфику, поэтому знание общих закономерностей социального поведения способствует пониманию экономического поведения, но недостаточно для того, чтобы точно его описать и тем более адекватно его объяснить. Отсюда в экономической психологии формируются специальные и теоретические, и практические проблемы, требующие специальных разработок с помощью исследовательских методов, также имеющих свою специфику. При этом экономическая психология, формируя свой понятийный аппарат, дополняет и существенно развивает систему понятий социальной психологии.

3. Признавая тесную связь с социальной психологией, тем не менее, экономическая психология рассматривается в качестве самостоятельной отрасли психологии. Аргументация этому состоит в том, что существуют неперекрывающиеся проблемы и задачи, характерные для экономической, а не социальной психологии. Чаще всего таковыми выделяются исследования процессов принятия экономических решений индивидом в самых различных условиях, исследование суждений экономического содержания и т.п. Более того, в соответствии с такой позицией считается, что экономическая психология фрактически складывается на границах не только с социальной, но и индивидуальной психологией, общей теорией психических процессов, психологией личности и т.д. Отсюда вытекает признание во многом пересекающихся, но не перекрывающих полностью друг друга систем понятий социальной и экономической психологии. Примерно то же самое относится и к оценке методов исследования: экономическая психология способна проявить и проявляет на практике особенности своих исследовательских и практических методов, не отрицая принципиальное сходство с системой методов социальной психологии.

В настоящее время профессиональное осмысление данного вопроса находится в таком состоянии, когда еще слишком рано утверждать единственный вариант как принципиально верный или какой-то из них полностью отрицать как неверный. Фактически научная дискуссия о статусе экономической психологии не только не завершена, но и полностью открыта, так как даже не высказаны еще все возможные варианты рассмотрения ее статуса в современной психологии, а всякая дискуссия все-таки это предполагает. 
Междисциплинарность экономической психологии. Сегодня можно с полным основанием признать явно междисциплинарный характер в целом экономической психологии как отрасли знания.

Междисциплинарный характер исследований в экономической психологии проявляется на разных уровнях, типичных для такого рода отраслей психологической науки. Во-первых, в обобщенной форме междисциплинарность проявляется на внешнепсихологическом уровне, т.е. собственно на границах психологической и непсихологических наук, где экономическая психология фрактически зародилась и плодотворно продолжает развиваться.

Наиболее интересные разработки в настоящее время ведутся, на границах экономической психологии и этики. Это относится к этике широко понимаемого социально-психологического феномена делового общения в трудовой, управленческой и предпринимательской деятельности - научным поискам, ведущимся под руководством Э.Х. Локшиной в Санкт-Петербургском государственном университете экономики и финансов. Интеграция экономической психологии и деловой этики имеет место также в кросскультурных исследованиях бизнеса, которые выполнялись П.Н. Шихиревым в Высшей школе международного бизнеса Академии народного хозяйства при Правительстве РФ.

Во-вторых, в настоящее время характерными проявлениями ее междисциплинарности становятся более частные и конкретные формы интеграции экономической психологии на внутрипсихологическом уровне, т.е. с другими многочисленными отраслями психологии. Наиболее ярко эта закономерность развития проявляется на границах с двумя психологическими отраслями. На границах с этнической психологией за короткий период сформировалась экономическая этнопсихология во многом благодаря исследованиям научно-педагогического коллектива кафедры социальной и экономической психологии Иркутской государственной экономической академии. Под научным руководством А.Д. Карнышева выполнены фундаментальные работы в этой области, позволившие обосновать и сформировать указанную отрасль. На границах экономической психологии с психологией управления сформировалось новое научное направление исследований, разрабатываемое большим научным коллективом психологов под руководством В.П. Фоминых в Чувашском государственном университете и получившее название «Психолого-экономические проблемы управленческой деятельности».

Некоторым подтверждением этого же положения является содержание многих работ, выполненных на границах с социальной, исторической, организационной, политической, этнической, педагогической психологией, а также с психологией личности, труда и управления. Пере- 
численные и другие примеры позволяют сделать вывод о том, что развитие междисциплинарных исследований в современной экономической психологии происходит более интенсивно на внутрипсихологическом уровне, по сравнению с внешнепсихологическим.

В-третьих, для понимания подлинного междисциплинарного характера экономической психологии очень важным является следующий аспект его рассмотрения: экономическая психология постепенно приобретает так называемый двойной сmamyс в системе наук. Как относительно самостоятельная отрасль она становится и развивается и в психологической, и в экономической науках, причем, хотя и взаимосвязано, но одновременно и относительно независимо. Как в свое историческое время существовали (а в некоторой степени это существует и до сих пор) психологическая инженерная психология и техническая инженерная психология, по аналогии, психологическая и социологическая социальная психология, психологическая и медицинская клиническая психология и т.п., так сегодня можно говорить об экономической и психологической экономической психологии.

Роль экономической психологии в развитии психологчческой и экономической наук. Становление и развитие экономической психологии как относительно самостоятельной отрасли психологии, естественно, стало возможным благодаря использованию научных направлений из ее «материнских», то есть породивших ее наук. Однако этот процесс достаточно быстро (и это тоже естественно) перестает быть односторонним, а постепенно переходит в процесс взаимного обогащения. Сейчас уже абсолютно ясно, что развитие экономической психологии дает много полезного для современной психологической науки в целом, на чем необходимо остановиться специально.

1. Исследования в области экономической психологии способствуют решению фундаментальной проблемы всей психологической науки - социально-экономической детерминации психологии и, в частности сознания человека и его различных общностей. Вопрос о том, в какой степени различные психологические компоненты человека как индивида, личности, субъекта деятельности и индивидуальности (по Б.Г. Ананьеву) определяются материально-экономическими условиями его жизнедеятельности - этот традиционный для психологической науки вопрос, который ограничивался философско-методологическим аспектом его анализа, характерным для длительного периода развития психологии, становится непосредственным предметом специально организованных исследований именно в экономической психологии. Разработка психоэкономической проблемы крайне важна для более глубокого понимания психологии современного человека, закономерностей ее функционирования и развития, а также для продвижения в понимании 
роли социально-экономических фракторов в формировании этих сложнейших явлений.

2. Экономическая психология существенно обогащает психологическую науку тем, что вводит в научный оборот и содержательно разрабатывает целый ряд новых для психологии понятий, без которых невозможно в полной мере описать и представить психологическую природу человека. Среди таких понятий и, соответственно, стоящих за ними изучаемых феноменов можно было бы назвать большой их ряд: экономическое поведение и экономическое сознание, собственность и собственник, богатство и бедность, денежные установки и польза, выгода и расчет, а также многое другое, что в совокупности может составить важнейшую экономико-психологическую характеристику человека и различных социальных групп.

3. Реальное взаимное обогащение происходит и в развитии методических средств исследования в экономической психологии, пожалуй, как ни в какой другой отрасли психологической науки столь интегрально используются и строгие экспериментальные исследования, и методы качественного анализа, и различные варианты применения программ, основанных на комбинировании качественно-количественных методов. В этой связи развитие экономической психологии хорошо иллюстрирует принципиальные возможности объединения различного типа методов исследования и интеграции номотетического и идеографического типов знания, хотя в настоящее время тенденция в развитии методов такова, что наиболее интенсивно совершенствуются приемы и способы качественного исследования. Если говорить о более частных вкладах экономической психологии, то, например, она привнесла в психологическую науку совершенно новое содержание метода дневников, который был известен в экономических исследованиях, и который может быть использован не только для ведения учета структуры расходов, но и для анализа структуры жизнедеятельности (занятий) личности или малой группы, в частности, как метод психологического исследования семьи или первичной группы и т.п.

Другой - специальный - вопрос состоит в том, а что дает развитие экономической психологии самой экономической науке. Конечно, на этот вопрос должны ответить сами экономисты, однако, существуют некоторые очевидные, лежащие как бы «на поверхности» положения, о которых тоже следует сказать.

Во-первых, экономическая наука также изучает человека, но прежде всего человека экономического, что, как многократно показывала историческая практика, является важной, но односторонней его характеристикой. Экономическая психология, пользуясь общепсихологической теорией, «поставляет» экономистам такие дополнительные психологи- 
ческие сведения о человеке, которые позволяют во многом объяснить закономерности его экономического поведения, а нередко, именно благодаря психологическим сведениям, вносить коррекции в выведенные экономические закономерности. В этом отношении наиболее полезными оказываются психологические данные о процессах индивидуального или группового принятия решений, мотивационной структуре человека, взаимосвязях и взаимных влияниях различных психологических компонентов: потребностей, мотивов, характера, способностей, направленности и т.д. Именно результаты экономико-психологических исследований позволили экономистам понять природу нерационального экономического поведения и в целом разрабатывать и включать в экономические модели фрактор «нерационального человека».

Во-вторых, экономическая психология способствует выявлению реальной роли экономических условий, фракторов, френоменов и т.п. в жизнедеятельности человека, которые изучаются экономической наукой, главным образом экономикой человека. Экономико-психологические исследования показывают, что между социально-экономическими условиями (факторами) или экономической средой и реальным экономическим поведением человека существуют опосредствующие фракторы в виде многочисленных системно организованных психологических феноменов (психологических фракторов), которые оказывают влияния и на экономическое поведение, и на формирование экономических условий, на состояние экономической среды. Поэтому психологические факторы крайне важно учитывать в экономических разработках.

Спецификация экономической психологии в начале ее становления происходила не по системам понятий и используемым методам, так как они были заимствованы из породивших ее базовых наук, а по содержанию предмета исследований, который в таком виде не был характерен ни для экономической, ни для психологической наук. Наряду с предметом исследования к признакам ее спецификации могут быть отнесены способы интерпретации полученных результатов исследования и некоторые особенности его организации. По мере развития экономической психологии совокупность таких признаков, естественно, будет возрастать по самым разным составляющим научной отрасли: не только по предмету исследования, но и его объектам, методам, используемым понятиям и т.Д., порождая тем самым и качественно новое состояние экономической психологии.

Само по себе возникновение экономической психологии как некоторой «зоны» интеграции экономистов и психологов представляет собой интересный социально-психологический феномен тем, что объединяются специалисты с очень разными профессиональными менталитетами, системами научных представлений. Если их кратко представить, то 
можно выделить главное различие в парадигмах выполняемых экономистами и психологами исследований.

Экономисты стремятся разрабатывать такие социальноэкономические условия, внедрять такие экономические механизмы и модели, которые способствуют человеку или социальным группам, целым организациям или регионам экономично работать, добиваться доходов, наращивать прибыль и т.п.

Психологи же считают, что в принципе не может быть универсальных социально-экономических механизмов, одинаково действующих на самые различные категории людей. Разрабатываемые и предлагаемые экономистами условия и механизмы реально срабатывают лишь на части людей, характеризующихся определенной структурой мотивации, системой ценностей, направленностью личности или группы. А у других категорий работников может наблюдаться прямой отказ или мягче - нежелание работать в предлагаемых экономических условиях, нежелание больших доходов или прибыли, если они, например, связаны с повышенными рисками или сопряжены с напряженным, тем более продолжительным трудом и т.д. Психологическая парадигма в исследованиях предполагает обязательно многофакторную систему объяснений одной и той же формы поведения в одних и тех же условиях, но разных людей. Среди них, конечно же, отводится определенное и достаточно важное место экономическим факторам, но они легко могут перестать быть решающими, их влияние может легко нивелироваться или как-то подругому изменяться под воздействием совсем других факторов, которые для конкретного человека являются более и даже значительно более значимыми и важными в жизни. И такими факторами часто являются именно психологические, но далеко не только. Можно говорить также о морально-этических (нравственных) факторах, о состоянии физического здоровья и многом другом, что опосредствует, трансформирует, поразному изменяет действие экономических условий, механизмов, факторов и т.п. Все это в совокупности позволяет психологам подвергать сомнениям те экономические разработки, которые игнорируют в своих моделях действие многочисленных психологических феноменов.

Поэтому складывающаяся интеграция экономистов и психологов в области экономической психологии дает возможности психологам более глубоко понимать значение универсальных моделей, описывающих экономические явления в том числе применимых к описанию и объяснению экономического поведения человека, а экономистам - понимать роль психологических переменных в процессе и последствиях реализации экономических разработок.

В настоящее время во многом сохраняется выделенный выше феномен двух экономических психологий - экономической и психологиче- 
ской, так как экономико-психологические исследования, выполняемые экономистами и психологами, несут на себе яркий «отпечаток» соответствующих «материнских» наук. Этот феномен является достаточно традиционным для многих междисциплинарных отраслей знания, особенно на стадии их становления. Дальнейшая же история у каждой междисциплинарной науки обычно своя, что является совершенно естественным. Дальнейшее развитие экономической психологии тоже возможно принципиально различными путями, и один конкретный из них спрогнозировать чрезвычайно затруднительно.

Заключение: некоторые итоги. Подводя итоги предварительному анализу развития экономической психологии в контексте современной психологической науки в целом, можно отметить несколько особенностей этого развития. Во-первых, необходимо еще раз подчеркнуть интенсивность развития экономической психологи, которое имело место во 2-ой половине 90-х годов XX века и в начале XXI в. Во-вторых, нужно отметить историческую преемственность различных этапов зарождения, становления и развития отечественной экономической психологии. Втретьих, следует выделить более интенсивное развитие внутрипсихологического уровня междисциплинарных исследований в экономической психологи, по сравнению с внешнепсихологическим. В-четвертых, необходимо иметь в виду оформляющуюся тенденцию в развитии относительно самостоятельного двойного статуса экономической психологии: в экономической и психологической науках. В-пятых, целесообразно отметить некоторую «мозаичность» в уже сложившейся структуре современной экономической психологии и в продолжающих формироваться новых научных направлениях исследований. Структурные части, составляющие экономическую психологию, пока остаются слабо связанными по их содержанию и относительно автономно развивающимся областями. В-шестых, можно констатировать сохраняющуюся высокую степень зависимости развития экономической психологии от практических потребностей современного общества, от общественной ее востребованности. Потенциал, если так можно выразиться, автономного «саморазвития» экономической психологии пока остается невысоким. В-седьмых, необходимо отметить, что формировалась экономическая психология как междисциплинарная научно-практическая отрасль психологи, поэтому ведущее место в ней по-прежнему занимают практически ориентированные исследования и разработки.

\section{Лumepamypa}

1. Алешина И.В. Поведение потребителей. М.: Фаир-Пресс, 1999. 384 с. 
2. Визир В.В. Социально-психологический анализ формирования рыночного экономического мышления. Дисс. ... канд. психол. наук. М., 1994. 138 c.

3. Дейнека О.С. Экономическая психология: социально-политические проблемы. СПб.: Изд-во СПбГУ, 1999. 240 с.

4. Журавлев А.Л., Купрейченко А.Б. Нравственно-психологическая регуляция экономической активности. М.: Изд-во «Институт психологии РАН», 2003. $436 \mathrm{c.}$

5. Китов А.И. Экономическая психология. М.: Экономика, 1987. 303 с.

6. Малахов С.В. Основы экономической психологии. М., 1992. 63 с.

7. Марцинкевич В.И., Соболева И.В. Экономика человека. М.: Аспект Пресс, 1995. 286 c.

8. Нгуен Минь Фыонг. Экономическое сознание и закономерности его развития в условиях перехода «постсоциалистического» общества к рыночным отношениям (на примере Вьетнама). Дисс. ... канд. фрилос. наук. М., 1995. 152 с.

9. Позняков В.П. Психологические отношения и деловая активность российских предпринимателей. М.: Изд-во «Институт психологии РАН», 2001. 240 c.

10.Позняков В.П. Психологические отношения субъектов экономической деятельности. М.: Изд-во «Институт психологии РАН», 2000. 220 с.

11.Попов В.Д. Психология и экономика. М.: Советская Россия, 1989. $304 \mathrm{c}$.

12.Проблемы экономической психологии. Том 1 / Отв. ред. А.Л. Журавлева, А.Б. Купрейченко. М.: Изд-во «Институт психологии РАН», 2004. $620 \mathrm{c}$.

13.Социальная психология экономического поведения / Отв. ред. А.Л. Журавлев, Е.В. Шорохова. М.: Наука, 1999. 237 с.

14.Социально-психологическая динамика в условиях экономических изменений / Отв. ред. А.Л. Журавлев, Е.В. Шорохова. М.: Изд-во «Институт психологии РАН», 1998. 295 с.

15.Социально-психологические исследования руководства и предпринимательства / Отв. ред. А.Л. Журавлев, Е.В. Шорохова. М.: Изд-во «Институт психологии РАН», 1999. 276 с.

16.Спасенников В.В. Экономическая психология: Учебн. пособие. М.: ПЕР СЭ, 2004.

17.Цимбалов И.П., Шевашкевич Г.М. Экономическое мышление и рыночное поведение. Саратов: СГТУ, 1996. 165 с.

18.Экономическая психология / Под ред. И.М. Андреевой. СПб.: Питер, 2000. 